Abstract P53 Table 1 Associations between clinical characteristics and odds of future poor clinical outcome

\begin{tabular}{|c|c|c|}
\hline cinical characteristic* & OR & $\mathbf{p}$ \\
\hline \multicolumn{3}{|l|}{ Age } \\
\hline \multicolumn{3}{|l|}{$<50$ [reference] } \\
\hline $50-59$ & 1.28 & 0.272 \\
\hline $60-69$ & 1.52 & 0.043 \\
\hline $70-79$ & 2.00 & 0.001 \\
\hline $80-69$ & 2.70 & 40.001 \\
\hline $90+$ & 5.21 & 40.001 \\
\hline Deprivation decile** & 0.95 & 40.001 \\
\hline \multicolumn{3}{|l|}{ BMI } \\
\hline \multicolumn{3}{|l|}{$18-24$ [reference] } \\
\hline$<18$ & 1.61 & 0.029 \\
\hline $25-29$ & 0.75 & 40.001 \\
\hline $30-34$ & 0.67 & 40.001 \\
\hline $35+$ & 0.87 & 0.195 \\
\hline History of pneumonia & 5.10 & 40.001 \\
\hline History of raised eosinophils $[=2 \%]$ & 1.18 & 0.011 \\
\hline History of Heart Failure & 1.44 & 0.007 \\
\hline Histo ry of Cerebrovascular Disease & 1.49 & 40.001 \\
\hline History of Peripheral Vascular Disease & 1.53 & 0.001 \\
\hline Histo ry of Anxiety Or Depression & 1.20 & 0.007 \\
\hline History of Chro nic Kidney Disease & 1.25 & 0.010 \\
\hline History of Rhinosinusitis & 0.75 & 0.001 \\
\hline \multicolumn{3}{|l|}{ Prescriptions in preceding 12 mon ths: } \\
\hline Nebulised bronchodilator & 2.24 & 40.001 \\
\hline ICS/LABA combination inhaler & 1.27 & 40.001 \\
\hline In haled LABA or LAMA & 1.71 & 40.001 \\
\hline Inhaled SAMA & 1.44 & 40.001 \\
\hline In haled SABA & 1.24 & 0.004 \\
\hline Constant & 0.28 & 40.001 \\
\hline
\end{tabular}

*Variables excluded from model due to statistical insignificance: gender, IHD, hypertension osteoporosis, GORD, diabetes, total number of comotbities.

**Decile 10 represents least deprived.

Results In our 'low risk' cohort of 6890 COPD patients, 5000 held sufficient data to be included in the analysis. After four years, $2211(44.2 \%)$ of those 5000 patients fell into the poor outcomes subgroup. As shown in Table 1, poor future outcomes were significantly associated with age, high deprivation decile, low BMI, certain comorbidities, a raised eosinophil percentage $(\geq 2 \%)$ and the prescription (in the preceding twelve months) of nebulised bronchodilators, inhaled bronchodilators and an ICS/ LABA combination inhaler. A BMI of $>25$ and rhinosinusitis were associated with a lower risk of poor future outcomes.

Conclusions Poor future clinical outcomes appear to be associated with certain clinical characteristics in a COPD database cohort deemed low risk by DOSE score. These findings warrant further validation in a clinical cohort and investigation into the effect of pre-emptive optimisation of these characteristics on health outcomes.

\section{P54 CAN MULTI-MORBID PHENOTYPES BE DESCRIBED IN PATIENTS WITH ADVANCED COPD USING CLUSTER ANALYSIS?}

${ }^{1} \mathrm{BD}$ James, ${ }^{1} \mathrm{NJ}$ Greening, ${ }^{2} \mathrm{~N}$ Toms, ${ }^{2} \mathrm{G}$ Woltmann, ${ }^{2} \mathrm{RC}$ Free, ${ }^{1} \mathrm{P}$ Haldar, ${ }^{2} \mathrm{MC}$ Steiner, ${ }^{2}$ RA Evans. 'University of Leicester, Leicester, UK; ${ }^{2}$ Institute for Lung Health, Respiratory BRU, University Hospitals NHS Trust, Leicester, UK

\subsection{6/thoraxjn--2016-209333.197}

Introduction and objectives Comorbidities have a negative effect upon outcomes in patients with COPD, and 'phenotypes' of comorbidity have been described. ${ }^{1}$ International guidelines recommend that comorbidities "should be looked for routinely". ${ }^{2}$ We aimed to objectively assess comorbidities, and investigate whether comorbidity phenotypes could be described using cluster analysis, in a cohort of patients with advanced COPD.

Methods Patients with advanced COPD were prospectively recruited to undergo a 'Comprehensive Respiratory Assessment' (CRA), as previously described. ${ }^{3} 13$ comorbidities were objectively assessed using validated definitions and their prevalence determined. K-means cluster analysis was applied with the objective measurements, and FEV1\%predicted. The clusters formed were compared with respect to demographic features, measures of health status, self-reported exacerbation frequency, and future cardiovascular risk.

Abstract P54 Table 1 Features of multi-morbid clusters

\begin{tabular}{|c|c|c|c|c|c|}
\hline Cluster: & $\begin{array}{c}1 \\
(n=51)\end{array}$ & $\begin{array}{c}2 \\
(n=50)\end{array}$ & $\begin{array}{c}3 \\
(n=36)\end{array}$ & $\begin{array}{c}4 \\
(n=36)\end{array}$ & $\begin{array}{c}5 \\
(n=30)\end{array}$ \\
\hline Age (years) & $62.3 \pm 8.5^{*}$ & $72.4 \pm 8.0^{+}$ & $64.2 \pm 9.1$ & $62.0 \pm 9.0^{*}$ & $65.4 \pm 7.4$ \\
\hline Gender ( $\%$ male) & $52.9 \%$ & $68.0 \%$ & $52.8 \%$ & $72.2 \%$ & $53.3 \%$ \\
\hline $\mathrm{FEV}_{1} \%$ predicted & $30.4 \% \pm 10.5 \%$ & $34.0 \% \pm 11.2 \%+$ & $25.6 \% \pm 6.5 \% *$ & $30.2 \% \pm 9.9 \%$ & $34.2 \% \pm 9.8 \%$ \\
\hline Participants using home oxygen (\%) & $35.3 \%$ & $42.0 \%$ & $30.6 \%$ & $25.0 \%$ & $53.3 \%+$ \\
\hline COPD Assessment Test (CAT) score & $30 \pm 5+$ & $24 \pm 7$ & $26 \pm 6$ & $21 \pm 7^{*}$ & $27 \pm 5$ \\
\hline Eosinophilia $(>0.3)$ in the past 3 years & $45.1 \%$ & $58.0 \%$ & $44.4 \%$ & $55.6 \%$ & $53.3 \%$ \\
\hline Antibiotic courses in past year & $5.0[2.0-7.0]$ & $4.0[2.0-6.0]$ & $5.0[2.0-7.0]$ & $2.0[1.0-5.0]^{*}$ & $3.0[2.0-6.0]$ \\
\hline Steroid courses in past year & $4.0[2.0-7.0]$ & $4.0[2.0-6.0]$ & $4.0[2.0-7.0]$ & $2.0[1.0-5.0]^{*}$ & $3.0[2.0-6.0]$ \\
\hline COPD hospitalisations in past year & $1.0[0.0-2.0]$ & $0.5[0.0-2.0]$ & $1.0[0.0-1.0]$ & $0.0[0.0-1.0]$ & $0.0[0.0-1.0]$ \\
\hline Total hospitalisations in past year & $1.0[1.0-3.0]$ & $1.0[0.0-3.0]$ & $1.0[1.0-2.0]$ & $1.0[0.0-2.0]$ & $1.0[0.0-2.0]$ \\
\hline Framingham risk (\%) & $7 \pm 5^{*}$ & $12 \pm 7+$ & $7 \pm 5^{*}$ & $11 \pm 7$ & $10 \pm 7$ \\
\hline $\begin{array}{l}\text { Data presented as mean } \pm \text { standard deviation and med } \\
* p<0.05 \text {, value of cluster is significantly lower than ren } \\
+p<0.05 \text {, value of cluster is significantly higher than re }\end{array}$ & $\begin{array}{l}\text { [interquartile range]. } \\
\text { ider of sample. } \\
\text { inder of sample. }\end{array}$ & & & & \\
\hline
\end{tabular}


Results Between June 2013 and December 2015, 246 patients with advanced COPD underwent a CRA: $61.0 \%$ male, mean (SD) age 66.0 (9.1) yrs, FEV1\%predicted 31.1\% (10.4\%). 98.4\% of participants were in GOLD combined assessment group D. The prevalence of the 13 comorbidities ranged from $68.8 \%$ (muscle wasting) to $7.7 \%$ (renal impairment). $93.9 \%$ of participants had at least two of the assessed comorbidities. Cluster analysis was applied to a subsample of 203 participants with sufficient data: five multimorbid clusters were identified according to a significantly higher prevalence of certain comorbidities: Cluster $1-$ psychological disease, Cluster 2 - left ventricular systolic dysfunction and anaemia, Cluster 3 - features of cachexia, Cluster 5 - features of metabolic syndrome and vitamin D deficiency. Cluster 4 had a significantly lower prevalence of comorbidities. Table 1 shows the differences between the five clusters in demographics, airflow limitation, health status, hospital admissions, use of antibiotics and steroids, and future cardiovascular risk.

Conclusions In this cohort of patients with advanced COPD, five multi-morbid phenotypes were identified. The phenotypes differed significantly in comorbidity prevalence, airflow limitation, health status and future coronary heart disease risk, however the number of hospital admissions in the past year was similar.

\section{REFERENCES}

1 Vanfleteren $L E$, et al. Clusters of comorbidities based on validated objective measurements and systemic inflammation in patients with chronic obstructive pulmonary disease. Am J Respir Crit Care Med 2013;187(7):728-35.

2 GOLD Global Strategy updated 2016.

3 Steiner MC, et al. Comprehensive respiratory assessment in advanced COPD: a 'campus to clinic' translational framework. Thorax 2015;70(8):805-8.

\section{P55 BENEFITS OF TIOTROPIUM/OLODATEROL ON SYMPTOMS AND HEALTH-RELATED QUALITY OF LIFE IN PATIENTS WITH MODERATE TO SEVERE COPD WITH CHRONIC BRONCHITIS AND/OR EMPHYSEMA}

${ }^{1}$ GT Ferguson, ${ }^{2}$ R Abrahams, ${ }^{3} \mathrm{~L}$ Bjermer, ${ }^{4} \mathrm{~L}$ Grönke, ${ }^{4} \mathrm{~F}$ VoB, ${ }^{5} \mathrm{D}$ Singh. ${ }^{1}$ Pulmonary Research Institute of Southeast Michigan, Farmington Hills, Michigan, USA; ${ }^{2}$ Department of Clinical Research, Morgantown Pulmonary Associates, Morgantown, West Virginia, USA; ${ }^{3}$ Department of Respiratory Medicine and Allergology, Lund University, Lund, Sweden; ${ }^{4}$ Boehringer Ingelheim Pharma GmbH and Co. KG, Ingelheim, Germany; ${ }^{5}$ The Medicines Evaluation Unit, Manchester, UK

\subsection{6/thoraxjnl-2016-209333.198}

Rationale Chronic bronchitis and emphysema are common features of chronic obstructive pulmonary disease (COPD), and are associated with adverse symptoms and poor health-related quality of life. The efficacy and safety of the combination of tiotropium $(\mathrm{T})$, a long-acting muscarinic antagonist, and olodaterol $(\mathrm{O})$, a long-acting $\beta_{2}$-agonist, has previously been established in COPD. This post hoc analysis of data from two Phase III studies was conducted to assess the effects of this combination on lung function, symptoms and health-related quality of life in patients with COPD with chronic bronchitis and/or emphysema.

Methods In two replicate, double-blind, parallel-group, placebocontrolled trials (OTEMTO 1 and 2 ), patients with COPD (GOLD 2-3) were randomised to receive T/O 5/5 $\mu \mathrm{g}$, T/O 2.5/5 $\mu \mathrm{g}, \mathrm{T} 5 \mu \mathrm{g}$ or placebo (P) for 12 weeks via Respimat ${ }^{\oplus}$ inhaler.1 Patients were classified as having chronic bronchitis, emphysema or both based on the investigator's clinical judgement. Lung-function testing was performed during the studies and forced expiratory volume in 1 second $\left(\mathrm{FEV}_{1}\right)$ area under the curve from $0-3$ hours $\left(\mathrm{AUC}_{0-3}\right)$ and trough $\mathrm{FEV}_{1}$ responses (i.e., change from baseline) calculated. Patients also completed the St George's
Respiratory Questionnaire (SGRQ) and the Mahler Transition Dyspnoea Index (TDI). Comparisons between T/O 5/5 $\mu \mathrm{g}$, T 5 $\mu \mathrm{g}$ and $\mathrm{P}$ at Week 12 are reported here.

Results The numbers of patients included in the analysis were as follows: bronchitis, 506; emphysema, 476; both bronchitis and emphysema, 206. The baseline characteristics of these three groups were generally comparable. After 12 weeks of treatment, there were significant improvements in $\mathrm{FEV}_{1} \mathrm{AUC}_{0-3}$ and trough $\mathrm{FEV}_{1}$ in all groups, with similar improvements across the groups. Significant improvements in SGRQ and TDI occurred in all groups at Week 12 and, again, these seemed to be similar (Table). Conclusions $\mathrm{T} / \mathrm{O} 5 / 5 \mu \mathrm{g}$ resulted in significant improvements in lung function, dyspnoea and health-related quality of life in patients with moderate to severe COPD with bronchitis, emphysema or both bronchitis and emphysema.

\begin{tabular}{|c|c|c|c|c|}
\hline $\begin{array}{l}\text { Comparison at } \\
\text { Week } 12\end{array}$ & & Bronchitis & Emphysema & Both \\
\hline \multirow[t]{2}{*}{$\begin{array}{l}\mathrm{FEV}_{1} \mathrm{AUC}_{0-3} \\
\text { response }\end{array}$} & $T / 0-P$ & $\begin{array}{l}0.306 \\
(0.264,0.347)^{b}\end{array}$ & $\begin{array}{l}0.321 \\
(0.277,0.366)^{b}\end{array}$ & $\begin{array}{l}0.285 \\
(0.203,0.366)^{b}\end{array}$ \\
\hline & $\mathrm{T} / 0-\mathrm{T}$ & $\begin{array}{l}0.097 \\
(0.055,0.138)^{b}\end{array}$ & $\begin{array}{l}0.121 \\
(0.079,0.162)^{b}\end{array}$ & $\begin{array}{l}0.086 \\
(0.008,0.165)^{\mathrm{a}}\end{array}$ \\
\hline \multirow[t]{2}{*}{$\begin{array}{l}\text { Trough FEV } 1 \\
\text { response }\end{array}$} & $T / 0-P$ & $\begin{array}{l}0.157 \\
(0.115,0.199)^{b}\end{array}$ & $\begin{array}{l}0.178 \\
(0.137,0.220)^{b}\end{array}$ & $\begin{array}{l}0.147 \\
(0.081,0.212)^{b}\end{array}$ \\
\hline & $\mathrm{T} / 0-\mathrm{T}$ & $\begin{array}{l}0.024 \\
(-0.018,0.066)\end{array}$ & $\begin{array}{l}0.044 \\
(0.004,0.085)^{a}\end{array}$ & $\begin{array}{l}0.021 \\
(-0.044,0.087)\end{array}$ \\
\hline \multirow[t]{2}{*}{ SGRQ } & $T / 0-P$ & $\begin{array}{l}-6.16 \\
(-8.19,-4.13)^{b}\end{array}$ & $\begin{array}{l}-6.76 \\
(-8.87,-4.65)^{b}\end{array}$ & $\begin{array}{l}-6.76 \\
(-10.06,-3.47)^{b}\end{array}$ \\
\hline & $\mathrm{T} / 0-\mathrm{T}$ & $\begin{array}{l}-2.63 \\
(-4.66,-0.61)^{\mathrm{a}}\end{array}$ & $\begin{array}{l}-2.24 \\
(-4.33,-0.16)^{\mathrm{a}}\end{array}$ & $\begin{array}{l}-3.10 \\
(-6.40,0.20)\end{array}$ \\
\hline \multirow[t]{2}{*}{ TDI } & $T / 0-P$ & $\begin{array}{l}2.11 \\
(1.52,2.69)^{b}\end{array}$ & $\begin{array}{l}2.22 \\
(1.63,2.81)^{b}\end{array}$ & $\begin{array}{l}2.43 \\
(1.47,3.38)^{b}\end{array}$ \\
\hline & $\mathrm{T} / 0-\mathrm{T}$ & $\begin{array}{l}0.61 \\
(0.02,1.19)^{\mathrm{a}}\end{array}$ & $\begin{array}{l}0.74 \\
(0.16,1.32)^{\mathrm{a}}\end{array}$ & $\begin{array}{l}0.53 \\
(-0.43,1.49)\end{array}$ \\
\hline
\end{tabular}

Adjusted mean (95\% confidence interval) differences

${ }^{a} \mathrm{p}<0.05 ;{ }^{b} \mathrm{p}<0.001$

\section{REFERENCE}

1 Singh $\mathrm{D}$, et al. Tiotropium + olodaterol shows clinically meaningful improvements in quality of life. Respir Med 2010; 109(10):1312-9.

Funding Boehringer Ingelheim.

Please refer to page A271 for declarations of interest in relation to abstract P55.

\section{P56 EFFICACY AND SAFETY OF LONG-ACTING BETA AGONISTS + LONG ACTING MUSCARINIC ANTAGONISTS VS. LONG-ACTING BETA AGONISTS + INHALED CORTICOSTEROIDS IN COPD: A META- ANALYSIS}

RE Villalobos, A David-Wang, J Magallanes. University of the Philippines-Philippine General Hospital, Manila, Philippines

\subsection{6/thoraxjnl-2016-209333.199}

Background and significance Current Global Initiative for Chronic Obstructive Lung Disease (GOLD) guidelines recommend the use of long-acting beta agonists (LABA) plus inhaled corticosteroids (ICS), or long-acting muscarinic antagonists (LAMA) for the treatment of patients with moderate to severe 